\title{
Percentage of Births to Mothers Who Reported Smoking Cigarettes at Any Time During Pregnancy, by Urbanization Level* of County of Residence - United States, 2020
}

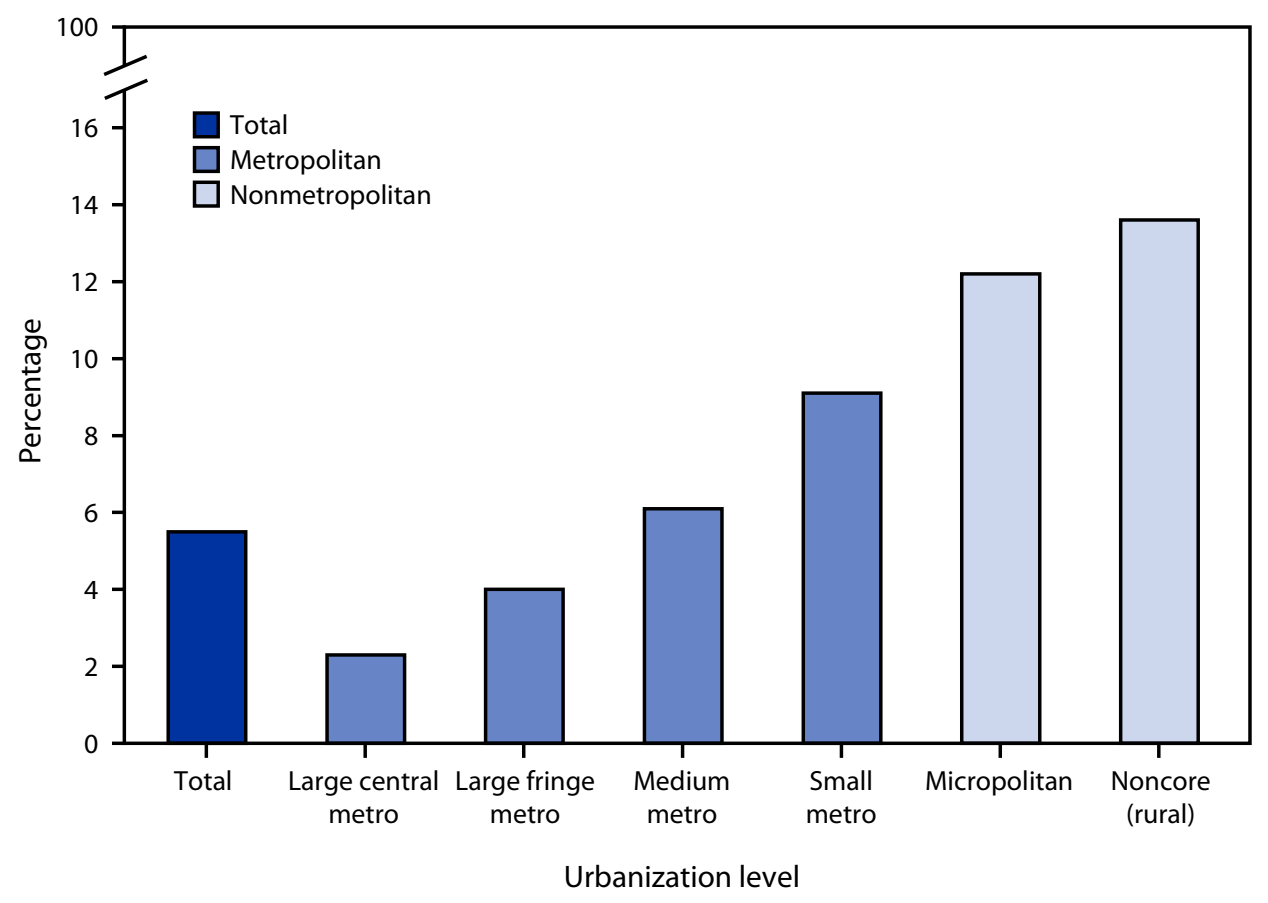

\footnotetext{
* Urbanization level is based on county of residence using the National Center for Health Statistics Urban-Rural Classification Scheme for Counties. http://www.cdc.gov/nchs/data/series/sr_02/sr02_166.pdf
}

In 2020,5.5\% of all births were to women who reported smoking cigarettes at any time during pregnancy. This percentage was lowest in large central metropolitan areas (2.3\%) and increased as the county of residence became less urbanized, reaching a high of $13.6 \%$ in the most rural (noncore) counties.

Source: National Vital Statistics System, natality file. https://wonder.cdc.gov/natality-expanded-current.html Reported by: Isabelle Horon, DrPH, ibh3@cdc.gov, 301-458-4555; Anne Driscoll, PhD. 